\title{
Centro presidencial: Presidencias y Centros de Gobierno en América Latina, Estados Unidos y Europa
}

\author{
Jorge Lanzaro (coordinador)
}

Editorial Tecnos, Madrid, 2018, 437 páginas.

\section{Ignacio Santoro}

La política tiende a la personalización. Los primeros mandatarios son cada vez más vistos como figuras monistas que concentran bajo su persona los aciertos y errores de un gobierno. Sin embargo, los primeros ministros y los presidentes no gestionan solos. Todo líder posee un equipo que apoya, asiste y refuerza su autoridad. Por ello el libro compilado por Jorge Lanzaro, Centro Presidencial, busca trascender el estudio de la figura personal del primer mandatario y centrarse en los Centros de Gobierno (CdG) o Centros Presidenciales (CP).

La riqueza del trabajo se encuentra, por un lado, en la diversidad de casos estudiados por prestigiosos académicos, desde la inclusión del leading case, Estados Unidos, hacia los estudios de presidencialismos latinoamericanos, pero también de algunos parlamentarismos europeos. Esta heterogeneidad muestra al libro como una útil herramienta de análisis comparado.

El trabajo comienza con una breve introducción donde se define al CP o CdG como los núcleos que apoyan directamente la labor de los jefes de gobierno, mediante diversas funciones, concentradas en las oficinas del Poder Ejecutivo. Las instituciones que llevan adelante estas tareas pueden ser tanto formales como informales.

En los siguientes dos capítulos se estudia el caso argentino. En primer lugar, Marcelo Camerlo y María Eugenia
Coutinho analizan las instituciones que compusieron el Centro Presidencial durante el período 1983 2014. Los autores destacan que el CP argentino varió de acuerdo a las estrategias de construcción de poder de cada presidente. A pesar de ello, durante el período estudiado el tamaño del CP se mantuvo estable y ante el surgimiento de nuevas funciones dentro de la órbita del Ejecutivo, estas fueron absorbidas por el gabinete.

Alejandro Bonvecchi, por otro lado, toma un eje diferente al analizar cómo los presidentes crean estructuras dentro de la presidencia para interceder en la política económica. Bonvecchi propone que el CP creció cuando se encontraron momentos de estabilidad económica. En cambio, ante períodos de crisis económica, se delegó la conducción de la política económica al Ministerio de Economía o al propio presidente.

En el tercer capítulo Magna Inácio, analiza el caso brasileño tomando los últimos siete gobiernos (hasta la primera presidencia de Dilma Rousseff). Brasil ha sido reiteradamente estudiado debido a la particularidad que presentan los Gobiernos de Coalición. Los mismos parten de la lógica del intercambio de apoyo parlamentario por puestos ministeriales, debido a un sistema de partidos muy fragmentados donde es necesario la formación de coaliciones para obtener mayorías parla- 
mentarias. El CP ha seguido la misma lógica del intercambio y en términos generales funcionó de manera conjunta con el gabinete, logrando estabilidad en el gobierno.

Chile comparte con Brasil el poseer gobiernos de coalición. En este libro, Peter Siavelis estudia los cuatro gobiernos de la Concertación desde el retorno democrático (1990 2010). En el caso chileno, el reparto de ministerios se determinó según el peso electoral de los miembros de la coalición (fórmula de cuoteo). Sin embargo, el cuoteo convivió con la incorporación de asesores informales, quienes tomaron algunas funciones del CP. Esta dinámica estuvo presente durante la administración tanto de Eduardo Frei como Ricardo Lagos, pero no bajo la presidencia de Patricio Aylwin. Michel Bachelet, en cambio, tuvo un CP reducido al verse desprestigiado el sistema de cuoteo y de asesores informales.

En los casos de Colombia, México y Perú, el CP se incrementa e institucionaliza logrando mejorar la acción de gobierno, así como también una centralización del control en manos del presidente. Luis Bernando Mejía Guinand y Felipe Botero Jaramillo, estudian el surgimiento y la institucionalización del CP colombiano. El Departamento Administrativo de la Presidencia de la República (DAPRE), organismo encargado de las tareas propias del CP, es creado en 1956, acrecentando su institucionalidad de manera sostenida, la cual realiza un salto en el año 1990, al adquirir una mayor cantidad de funciones. A partir de 2002, Colombia ha tendido a formar coaliciones de gobierno. Por ello, el CP compite y en ocasiones sustituye las tareas de los ministros.

México es estudiado por José Luis Méndez quien escruta las presidencias de Vicente Fox (2000 2005), Felipe Calderón (2005 -2010) y Enrique Peña Nieto (2010 -2015). Desde un punto de vista metodológico el artículo resulta interesante al crear una tipología en torno a la relación entre el presidente y su CP. A partir de ella, la CP durante la presidencia de Fox, fue guiado por el principio de «Incertidumbre Competitiva», donde existió un Chief of staff fuerte y una división clara del trabajo, mientras que Calderón y Peña Nieto siguieron un principio de «Certidumbre Competitiva» sin un jefe ni tareas claras, y con competencia entre las áreas. Sin embargo, como balance de las tres presidencias el tamaño del CP se mantuvo relativamente pequeño.

En Perú en cambio, las transformaciones en el CP fueron determinantes en la acción de gobierno. Para demostrar ello, Salvador Peralta, toma como objeto de análisis las dos presidencias de Alan García (1985 1990 y 2006 2011). El autor entiende que la diferencia entre la primera presidencia de García (fallida) y la segunda (relativamente exitosa) tiene su raíz un cambio en el plano organizacional con un $\mathrm{CP}$ más fuerte, repercutiendo en una mayor eficiencia en las políticas de gobierno.

Jorge Lanzaro explica que, a diferencia del resto de los casos latinoamericanos, en Uruguay entre 1985 y 2005 el CP se mantuvo con una estructura reducida y una centralización acotada. Asimismo, los cambios en el CP no se dieron dentro de gobierno de coalición sino en el gobierno mayoritario de un solo partido, el Frente Amplio (2005 2015).

Hacia el final del libro se compilan tres casos europeos y se dedica un capítulo a Estados Unidos. Bert A. Rockman es el encargado del estudio 
Reseñas

del caso norteamericano, destacando sus orígenes constitucionales y cómo se fueron moldeando los poderes del Ejecutivo a partir del enfrentamiento con el Poder Legislativo y los poderes locales. Frente a ellos, la mediación por parte de la Justicia ofició como árbitro en la distribución de potestades a partir de la interpretación de la Carta Magna.

Dentro de los modelos europeos, Mario Kölling estudia el caso alemán, tomando el gobierno de Konrad Adenauer (1949 1963) como puntapié inicial hasta el actual mandato de Angela Merkel. El CP alemán tiene como principal función la coordinación de la estructura jerárquica que compone el Poder Ejecutivo, así como también la de los actores políticos locales y, en los casos de coaliciones simétricas, con los partidos que la componen. Asimismo, en los últimos años el CP se ha vuelto más activo al impulsar políticas, interfiriendo en el rol de los ministerios.

Gran Bretaña tiene una larga tradición de un poder centralizado en el Ejecutivo, explica Martin J. Smith. Sin embargo, el CdG ha sido tradicionalmente débil, siendo los ministros muy poderosos. Por ello, desde 1980 en adelante, los primeros mandatarios busca- ron expandir sus recursos políticos y centralizar la toma de decisiones en su persona. No obstante, si bien se ha reforzado e institucionalizado el CdG formal, este proceso encontró limitaciones producto de la fortaleza de los ministerios.

Finalmente, Juan Luis Paniagua analiza los gobiernos españoles desde el retorno democrático en 1977 hasta 2015. La Constitución española dotó de un gran poder a la Presidencia. Sin embargo, el CP demoró hasta el gobierno de Felipe Gonzáles (1982) en consolidarse. A partir de ello, cada uno de los presidentes adaptó las estructuras de la presidencia a su conveniencia y criterio, manteniendo, sin embargo, las instituciones, estructuras y procesos. En su trabajo, Paniagua analiza exhaustivamente cada uno de estos elementos, combinados con la estructura interna de los partidos, la comunicación política y el estilo de las campañas españolas.

Como conclusión, Centro Presidencial resulta novedoso al ocupar un espacio faltante en la literatura politológica, incorporando una gran cantidad de casos, pero también al aportar insumos metodológicos y teóricos útiles para la realización de estudios futuros. 